\title{
Fetal alcohol spectrum disorders in Australia - the future is prevention
}

\section{Elizabeth J Elliotta-e}

a Discipline of Paediatrics and Child Health, Sydney Medical School, University of Sydney, NSW, Australia

b The Sydney Children's Hospitals Network, NSW, Australia

c National Health and Medical Research Council, Canberra, ACT, Australia

d Australian Paediatric Surveillance Unit, Sydney, NSW, Australia

e Corresponding author: elizabeth.elliott@health.nsw.gov.au

\section{Article history}

Publication date: March 2015

Citation: Elliott E. Fetal alcohol spectrum disorders in Australia - the future is prevention. Public Health Res Pract. 2015;25(2):e2521516. doi: http://dx.doi. org/10.17061/phrp2521516

\section{Key points}

- Prenatal brain injury cannot be reversed, so prevention of fetal alcohol spectrum disorders (FASD) is key

- A federal parliamentary inquiry and subsequent action plan have focused attention on the need to prevent FASD

- Prevention should be evidence based and evaluated, but Australia lacks FASD surveillance and a national register to measure the success of prevention programs

- Prevention requires education, adequate drug and alcohol services, support of initiatives such as community-led alcohol restrictions, and enforcement of existing legislation

- Measures to decrease access to alcohol including pricing, and restrictions on promotion and advertising of alcohol, are crucial

\section{Abstract}

Fetal alcohol spectrum disorders (FASD) are increasingly recognised throughout Australia as important, but preventable, disorders that result in lifelong problems with health and learning, mental health, behaviour and substance misuse. The role of this article is to highlight current efforts, which are in their infancy, to recognise and prevent FASD in Australia.

A federal parliamentary inquiry into FASD (2011), development of an Australian Government 'action plan' to prevent FASD (2013) and the announcement in June 2014 of government funding to progress the plan and appoint a National FASD Technical Network have focused attention on the need for FASD prevention in Australia. Other welcome developments include the formation of Parliamentarians for the Prevention of FASD (2011), revision of guidelines regarding alcohol use in pregnancy by the National Health and Medical Research Council (NHMRC; 2009) and provision of targeted funding for FASD research by the NHMRC (2013).

Initiatives by Indigenous communities to restrict access to alcohol and diagnose and prevent FASD have had a significant impact in high-risk communities. The National Organisation for FASD has an important ongoing advocacy and educational remit. Nongovernment organisations such as the Foundation for Alcohol Research and Education have contributed to prevention by developing resources to assist health professionals to advise women about the harms of alcohol use in pregnancy; encouraging men to abstain from alcohol during the pregnancy; drafting a national plan; and advocating for pregnancy warning labels on alcohol. Internationally, in 2014, a charter on prevention of FASD was published in The Lancet Global Health, and the World Health Organization released guidelines for identification and management of substance use in pregnancy.

Early recognition and support for individuals with FASD is crucial to prevent adverse secondary outcomes; however, primary prevention of alcohol use in pregnancy, and hence FASD, should be our future goal. The causal pathway to drinking in pregnancy is complex and requires a broad social ecological approach. Prevention will take time, must involve all government sectors and should incorporate primary, secondary and tertiary strategies to target both the broader community and populations at high risk of alcohol use during pregnancy. 


\section{Introduction}

The adage that "prevention is better than cure" is apt when applied to the tragedy of fetal alcohol spectrum disorders (FASD). Prevention is challenging and requires understanding of the complex social and ecological determinants of alcohol misuse during pregnancy, and strategies to interrupt the causal pathway. Prevention strategies must also address alcohol supply and promotion. Akin to the campaign to decrease harms from smoking in Australia, attempts to eradicate alcohol use in pregnancy and prevent FASD will take time and likely meet opposition.

Alcohol readily crosses the placenta and, because it is teratogenic, may irreparably damage the brain and other organs of the developing embryo and fetus. ${ }^{1}$ FASD is an umbrella term that includes a spectrum of disorders that may result from alcohol exposure in utero. FASD are associated with birth defects, facial dysmorphology, and problems with cognition, growth and development. They have lifelong implications and may lead to significant secondary impairments, including academic failure, substance abuse, mental ill-health, contact with the justice system, and difficulties living independently and obtaining and maintaining employment. ${ }^{1}$ The influence of alcohol exposure in utero on epigenetics, and later drinking behaviour and secondary outcomes, is not known.

\section{Overview}

Alcohol use is common in pregnant women in Australia..$^{1,2}$ In one representative sample of women aged 18-45 years, $89.4 \%$ consumed alcohol in the previous year but $39 \%$ were unaware of the potential for fetal harm. ${ }^{2,3}$ About $50 \%$ had heard of FASD but $16 \%$ were unaware that alcohol use during pregnancy could cause lifelong disabilities. About $20 \%$ of women had a 'neutral, tolerant or positive' attitude to alcohol use in pregnancy. Higher educational level predicted better knowledge of harms (odds ratio [OR] 5.62; 95\% confidence interval [Cl] 3.20 to 9.87 ) but not attitudes.

Of the 700 women who had previously given birth, 34\% reported drinking during their most recent pregnancy. 2,3 When asked what they would do in a future pregnancy, $31.6 \%$ said they would continue to drink alcohol. Intention to drink in future pregnancies was not associated with knowledge of harms to the fetus, but with a neutral or positive attitude to alcohol use in pregnancy (adjusted OR 5.1; 95\% Cl 3.6 to 7.1 ). ${ }^{3}$ Intention to drink was also associated with current risky drinking, drinking in a previous pregnancy and smoking. These findings identify high-risk groups, but indicate that education without attitudinal change will not change behaviour, posing a challenge for policy makers.

More than $50 \%$ of women identify health professionals as their preferred information source about alcohol use in pregnancy: almost all agree that health professionals should ask and advise about alcohol use in pregnancy, and more than $90 \%$ agree that health professionals should advise women to give up alcohol during pregnancy (Elizabeth Peadon, The Children's Hospital at Westmead, Sydney, pers. comm. Dec 2014). These results endorse the important role of clinicians in providing advice that might prevent FASD, but highlight a mismatch between women's and health professionals' attitudes. In one state-wide survey, only $45 \%$ of health professionals routinely asked about alcohol use during pregnancy, and $12 \%$ never asked. ${ }^{4}$ Health professionals were afraid of upsetting (10\%) and stigmatising (60\%) women. Many did not know what to advise and wanted educational resources. Failure to ask and advise about alcohol use represents a missed opportunity for both treating women and preventing FASD.

Lack of health professionals' knowledge about, and confidence to diagnose, FASD is a barrier to early treatment, which can both minimise secondary disabilities in an affected child and prevent a sibling being born with FASD. In one Australian study, more than half the children diagnosed by paediatricians with fetal alcohol syndrome already had an affected sibling, indicating missed opportunities for prevention. ${ }^{5}$ Education can change health professionals' knowledge and practice, and influence the advice they give about drinking in pregnancy. ${ }^{6}$

The causal pathway to alcohol use in pregnancy and FASD is complex. ${ }^{1}$ FASD, the end result of alcohol misuse in women, occur in an Australian society in which risky drinking is common and tolerated, and alcohol is easily accessible and cheap. Disadvantage (including overcrowded housing and limited access to education, training, employment and health services) is a determinant of alcohol misuse. Although alcohol use in pregnancy is problematic throughout Australia, there are identifiable high-risk groups. These include women in some remote Aboriginal communities where frequent risky drinking predominates, putting the fetus at high risk. These women say they drink to deal with stress (Heather D'Antoine, Menzies School of Health Research, Darwin, pers. comm. Dec 2014), including the impact of historical trauma; the stolen generations; loss of language, land and culture; domestic violence; and geographic isolation. These stresses add to the mix of causal factors and make solutions more challenging.

FASD deny a child the right to normal health and development, and prevention is an imperative. FASD confer a burden on individuals and families that is impossible to cost. Economic analyses confirm that FASD are expensive to society - in health, education, disability and justice. ${ }^{1}$ Internationally, the need for prevention is highlighted in a recently published charter on prevention of FASD. ${ }^{7}$ At the national level, prevention is a key pillar in the 2013 report from the Federal Parliament House of Representatives Inquiry - 'FASD, the hidden harm'. 8 The Australian Government's response to the inquiry 
(www.health.gov.au/internet/main/publishing.nsf/Content/ health-pubhlth-strateg-drugs-alcohol-index.htm), an action plan to reduce the impact of FASD, includes prevention. In June 2014, funding of $\$ 9.3$ million was announced for FASD programs, including a National FASD Technical Network to help implement the plan.

\section{Framework for FASD prevention}

Prevention strategies should be evidence based and evaluated; however, Australia lacks FASD surveillance and a national FASD register.

Primary prevention must be underpinned by an understanding of the causal pathway to drinking in pregnancy, and requires a collaborative, whole-ofgovernment approach. It is essential to create an environment in which risky drinking is regarded as unacceptable, and to apply proven measures to reduce access to and consumption of alcohol (such as pricing, volumetric taxation, limited number and opening hours of liquor outlets, and restrictions on alcohol advertising/ promotion). Existing legislation (e.g. laws that prevent serving alcohol to intoxicated clients) must be enforced.

Individual and community awareness can be improved through education that must engage women, men and children; be culturally sensitive; be informed by community knowledge, attitudes, values and drinking practices; and be consistent with national guidelines. ${ }^{9}$ Targeted education is important for high-risk groups. Awareness can be achieved through mass media campaigns, including the use of film, and pregnancy warning labels on alcoholic beverages - though labelling must be clearly visible with a cogent message. The June 2014 decision to extend a 'voluntary' code to the alcohol industry rather than to mandate labelling is disappointing. Education of professional groups in the areas of health, education and justice is crucial and requires dissemination of national policy. ${ }^{9}$ Empowerment of communities through advocacy, funding and practical help enables community-led initiatives to address alcohol misuse. Self-determination is exemplified by the Aboriginal communities of the Fitzroy Valley, who successfully lobbied for restrictions on take-away alcohol. Restrictions on alcohol-sponsored sporting and community events will also help to change attitudes. Ideally, all women attending a primary health care professional should be asked about their alcohol use to identify and manage misuse before pregnancy occurs.

Secondary prevention strategies to prevent harms from alcohol misuse in pregnancy (and harm to the fetus) include screening of women at antenatal visits and advice about alcohol use in pregnancy. This is a challenge because nearly half of pregnancies are unplanned, and health professionals often neglect to ask patients about alcohol. Recently published 'Women want to know' resources (www.alcohol.gov.au/internet/ alcohol/publishing.nsf/Content/wwtk) will assist health professionals to ask and advise before and during pregnancy. Clinicians must also discuss contraception with women who wish to continue drinking. Brief, effective therapeutic interventions for pregnant women who misuse alcohol include motivational interviewing ${ }^{10}$; for women with dependency, referral to drug and alcohol services and postnatal support is crucial.

Tertiary strategies are required to prevent the longterm secondary disabilities associated with FASD. This can be achieved in part through education and training of health professionals to enable early diagnosis and timely educational and health interventions, to maximise individual potential.

Although the young brain is adaptable, prenatal brain injury cannot be reversed so, for FASD, the future must be prevention.

\section{Acknowledgements}

The author is supported by an NHMRC Practitioner Fellowship (No. 1021480).

\section{Competing interests}

None declared

\section{References}

1. Burns L, Elliott E, Black E, Breen C, editors. Fetal alcohol spectrum disorders in Australia: an update. Canberra: Intergovernmental committee on drugs working party on fetal alcohol spectrum disorders. June 2012 [cited 2015 Jan 27]. Available from: www.nationaldrugstrategy.gov. au/internet/drugstrategy/publishing.nsf/Content/monofasd

2. Peadon E, Payne J, Henley N, D'Antoine H, Bartu A, O'Leary $C$, et al. Women's knowledge and attitudes regarding alcohol consumption in pregnancy: a national survey. BMC Public Health. 2010;10(1):510.

3. Peadon E, Payne J, Henley N, D'Antoine H, Bartu A, O'Leary $\mathrm{C}$, et al. Attitudes and behaviour predict women's intention to drink alcohol during pregnancy: the challenge for health professionals. BMC Public Health. 2011;11(1):584.

4. Payne J, Elliott E, D'Antoine H, O'Leary C, Mahony A, Haan E, et al. Health professionals' knowledge, practice and opinions about fetal alcohol syndrome and alcohol consumption in pregnancy. Aust N Z J Public Health 2005;29(6):558-64.

5. Elliott EJ, Payne J, Morris A, Haan E, Bower C. Fetal alcohol syndrome: a prospective national surveillance study. Arch Dis Child. 2008;93(9):732-7. 
6. Payne J, France K, Henley N, D'Antoine H, Bartu A, O'Leary C. Changes in health professionals' knowledge, attitudes and practice following provision of educational resources about prevention of prenatal alcohol exposure and fetal alcohol spectrum disorder. Paediatr Perinat Epidemiol. 2011;25(4):316-27.

7. Jonsson E, Salmon A, Warren KR. The international charter on prevention of fetal alcohol spectrum disorder. Lancet Glob Health. 2014;2(3):e135-7.

8. House Standing Committee on Social Policy and Legal Affairs. FASD: the hidden harm. Inquiry into the prevention, diagnosis and management of fetal alcohol spectrum disorders. Canberra: Commonwealth of Australia; 2012 [cited 2015 Jan 27]. Available from: www. aph.gov.au/Parliamentary_Business/Committees/House_ of_Representatives_Committees?url=spla/fasd/report.htm
9. National Health and Medical Research Council. Australian guidelines to reduce health risks from drinking alcohol. Canberra: Commonwealth of Australia; 2009 [cited 2015 Jan 27]. Available from: www.nhmrc.gov.au/ guidelines-publications/ds10

10. World Health Organization. Guidelines for the identification and management of substance use and substance use disorders in pregnancy. Geneva: World Health Organization; 2014 [cited 2015 Jan 27]. Available from: www.who.int/substance_abuse/publications/ pregnancy_guidelines/en/

\section{Copyright: @(1)(2)}

(C) 2015 Elliott. This article is licensed under the Creative Commons Attribution-NonCommercial-ShareAlike 4.0 International Licence, which allows others to redistribute, adapt and share this work non-commercially provided they attribute the work and any adapted version of it is distributed under the same Creative Commons licence terms. See: www.creativecommons.org/licenses/by-nc-sa/4.0/ 